\title{
Determining the activity of ${ }^{241} \mathrm{Pu}$ by liquid scintillation counting
}

\author{
J. A. Corcho Alvarado · Y. Nedjadi • \\ F. Bochud
}

Received: 15 March 2011/Published online: 28 April 2011

(C) Akadémiai Kiadó, Budapest, Hungary 2011

\begin{abstract}
Liquid scintillation counting (LSC) is one of the most widely used methods for determining the activity of ${ }^{241} \mathrm{Pu}$. One of the main challenges of this counting method is the efficiency calibration of the system for the low beta energies of ${ }^{241} \mathrm{Pu}\left(E_{\max }=20.8 \mathrm{keV}\right)$. In this paper we compare the two most frequently used methods, the CIEMAT/NIST efficiency tracing (CNET) method and the experimental quench correction curve method. Both methods proved to be reliable, and agree within their uncertainties, for the expected quenching conditions of the sources.
\end{abstract}

Keywords ${ }^{241} \mathrm{Pu} \cdot \mathrm{CIEMAT/NIST} \cdot$ Liquid scintillation counting $\cdot$ Counting efficiency

\section{Introduction}

Plutonium-241 (half-life $=14.33$ (4) years, $E_{\beta \max }=20.8$ (2) $\mathrm{keV}$ ) is one of the most important plutonium isotopes introduced into the environment as a result of the nuclear bomb tests (NBT), accidents in nuclear facilities and normal discharges from reprocessing plants [1-4]. ${ }^{241} \mathrm{Pu}$ is also found in large quantities in residues from nuclear reactor decommissioning activities [5]. Although this radioisotope is not important from the radiological point of view (low energy beta emitter, and short half-life), its decay daughter is highly radiotoxic $\left({ }^{241} \mathrm{Am}\right.$ : alpha emitter and relative long half-life). Therefore, the accurate determination of ${ }^{241} \mathrm{Pu}$ is

J. A. Corcho Alvarado $(\bowtie) \cdot$ Y. Nedjadi · F. Bochud Institute of Radiation Physics, University Hospital and University of Lausanne, Rue du Grand-Pré 1,

1007 Lausanne, Switzerland

e-mail: jose-antonio.corcho-alvarado@chuv.ch of special interest for the determination of the long-term radiation dose to the population and for the decommissioning of nuclear facilities and radioactive waste management [5-7]. Apart from these radiological interests, ${ }^{241} \mathrm{Pu}$ can also be combined with ${ }^{239,}{ }^{240} \mathrm{Pu}$ or ${ }^{241} \mathrm{Am}$ and used for determining the origin and age of plutonium materials and/or plutonium contaminations [1-3, 7-9].

The determination of ${ }^{241} \mathrm{Pu}$ activity is usually based on counting its low energy beta emissions by liquid scintillation counting-LSC $[2,3,7,8,10-13]$. New generations of LSC systems discriminate $\alpha$ and $\beta$ events which permits the measurement of the low-energy $\beta$ particles of ${ }^{241} \mathrm{Pu}$ in the presence of the $\mathrm{Pu} \alpha$-emitters [9]. This measuring method has several advantages like a relatively easy sample preparation and often high efficiency $[2,9]$. However, one of the main challenges of the LSC methods consists in the accurate determination of the counting efficiency $[2,7,9]$.

The most widely used approach to determine the counting efficiency is the experimental quench correction curve. This method requires the use of appropriate quenched standards of the same radionuclide whose activity is to be determined. The dependence of the efficiency on the quenching parameter is then determined by measuring the count rates of the quenched standards and their quenching parameters which are derived from the external standard spectra.

Adequate standards might, however, not be readily available in the laboratories [7, 9, 14]. This difficulty can be overcome by using the CIEMAT/NIST standard efficiency tracing method, known as CNET method $[1,7,15-$ 19]. In the CNET method, the experimental counting efficiency of one tracer radionuclide (tritium is often the most suitable) is determined for different degrees of chemical quench $[15,18,19]$. Then, the theoretical counting efficiency for both the tracer $\left({ }^{3} \mathrm{H}\right)$ and the radionuclide of 
interest (in our case ${ }^{241} \mathrm{Pu}$ ) are modeled using the theories of radioactive decay and energy transfer of the radiation to the scintillator for the experimental conditions. A universal curve is obtained, which allows one to determine the counting efficiency for any radionuclide of interest.

We conducted this work in order to study the extent to which the CNET method, using ${ }^{3} \mathrm{H}$ as an indicator of the performance of a standard LSC, can be used to obtain the efficiency for ${ }^{241} \mathrm{Pu}$. The paper presents and discusses the result of the efficiency calibration of an ultra low level LSC by the two approaches described above. The influence of the quenching degree and activity level have been studied using samples of known activity and the results of the quench correction curve were found to agree with the CNET within $\pm 2 \%$.

\section{Experimental section}

Materials and reagents

All reagents used in the experiments were of analytical grade (Fluka, Buchs, Switzerland). The ${ }^{241} \mathrm{Pu}$ standard solution $(6.2 \mathrm{~Bq} / \mathrm{g} \mathrm{u}=2 \%$ in $0.1 \mathrm{M} \mathrm{HCl}$ at the reference date of 27.05.2009) was traceable to a standard solution provided by AEA Technology, UK (code PKP10020, batch number 94/241/50). The ${ }^{3} \mathrm{H}$ standard solution (activity concentration of $88.65 \mathrm{~Bq} / \mu \mathrm{L}(\mathrm{u}=1.7 \%)$ on 13.3 .1980$)$ was provided by the Institut d'Electrochimie et de Radiochimie (EPFL, Lausanne, Switzerland). The cocktail Ultima Gold AB was supplied by Perkin Elmer.

\section{Laboratory equipments}

The measurements were conducted in an ultra low level liquid scintillation spectrometer Wallac Quantulus 1220 (PerkinElmer Inc., Finland) of the Institute of Radiation Physics (Switzerland). The Quantulus 1220 is equipped with a sealed source of ${ }^{152} \mathrm{Eu}(37 \mathrm{kBq})$ which is used to determine its spectral quench parameter $\operatorname{SQP}(E)$. The region of interest for ${ }^{241} \mathrm{Pu}$ was chosen between the channels 60 and 220. For a counting time of $360 \mathrm{~min}$, the typical background in this window is $1.3 \mathrm{cpm}$. This results in a detection limit of $9 \mathrm{mBq}$ for ${ }^{241} \mathrm{Pu}$ (a counting efficiency of $42 \%$ is assumed). $20 \mathrm{~mL}$ polyethylene liquid scintillation counter vials (Zinsser) were used for the study.

Methods

\section{Experimental ${ }^{241} \mathrm{Pu}$ quench correction curve}

A set of seven vials containing about $1 \mathrm{~g}$ of a ${ }^{241} \mathrm{Pu}-\mathrm{stan}-$ dard solution (in $0.1 \mathrm{M} \mathrm{HCl}$ ) and $19 \mathrm{~mL}$ of Ultima Gold AB was prepared gravimetrically. This geometry was chosen because it is very similar to the one used in previous studies in our laboratory [9]. Increasing amounts of the quenching agent $\mathrm{CCl}_{4}$ were added to the vials in order to decrease the counting efficiency (Table 2). Since the activities of ${ }^{241} \mathrm{Pu}$ are known, the measured net counting rates in the region of interest (channels 60-220) yield the counting efficiencies of ${ }^{241} \mathrm{Pu}$. The quenching parameter was measured for each sample with the external standard source of ${ }^{152} \mathrm{Eu}(37 \mathrm{kBq})$ of the LSC system. Then, the quench curve was obtained by plotting the counting efficiency versus the quenching parameter $\mathrm{SQP}(E)$.

\section{CNET method}

A set of five vials containing well known amounts of a ${ }^{3} \mathrm{H}$ standard solution and $19 \mathrm{~mL}$ of the scintillation cocktail Ultima Gold $\mathrm{AB}$ was prepared gravimetrically. Increasing amounts of the quenching agent $\mathrm{CCl}_{4}$ were added to the vials (Table 3 ). The counting efficiencies of ${ }^{3} \mathrm{H}$ were obtained from the net counting rates in the region of interest (channels 60-220), and the calibration curve was obtained similarly to the one for ${ }^{241} \mathrm{Pu}$.

The theoretical relationship of the efficiency of the tracer ${ }^{3} \mathrm{H}\left({ }^{\varepsilon_{3} \mathrm{H}}\right)$ and the efficiency of the radionuclide of interest ${ }^{241} \mathrm{Pu}\left({ }^{2241} \mathrm{Pu}\right)$ were obtained using the code CN2004 [15]. The nuclear data of ${ }^{241} \mathrm{Pu}$ and ${ }^{3} \mathrm{H}$ used for the model are given in the Table 1 (ex. maximal and average beta energy, and shape parameter).

The maximum beta energies of ${ }^{3} \mathrm{H}$ and ${ }^{241} \mathrm{Pu}$ are very close; however their Fermi distribution maxima are slightly different (Table 1). ${ }^{241} \mathrm{Pu}$ maximum is shifted to lower energies relative to tritium, primarily due to the Coulombic effect. The spectrum shape of ${ }^{241} \mathrm{Pu}$ is also not very well known [20]. An allowed shape was assumed for the ${ }^{241} \mathrm{Pu}$ when running the code despite the fact that its $\beta$-decay is a first forbidden transition. The computed efficiencies depend on the value used for $\mathrm{kB}$. This parameter was taken equal to $0.0075 \mathrm{MeV} / \mathrm{cm}$ based on previous studies [16]. The density of the Ultima Gold $\mathrm{AB}$ was taken as $0.96 \mathrm{~g} / \mathrm{cm}^{3}$, and its chemical composition as: C $(76.33 \%)$, $\mathrm{H}(9.73 \%), \mathrm{N}(0.05 \%), \mathrm{O}(13.79 \%)$ and $\mathrm{P}(0.10 \%)$.

Table 1 Selected nuclear data for ${ }^{241} \mathrm{Pu}$ and ${ }^{3} \mathrm{H}$

\begin{tabular}{lll}
\hline Parameter & ${ }^{241} \mathrm{Pu}$ & ${ }^{3} \mathrm{H}$ \\
\hline Half-life (years) & $14.33 \pm 0.04$ & $12.312 \pm 0.025$ \\
$E_{\beta \max }(\mathrm{keV})$ & $20.8 \pm 0.2$ & $18.564 \pm 0.003$ \\
$E_{\beta \text { ave }}$ & $5.8 \pm 0.1$ & $5.68 \pm 0.01$ \\
Atomic mass (g) & 241.0568 & 3.016 \\
Alpha particle branch & $(2.46 \pm 0.01) \times 10^{-5}$ & - \\
Shape factor & 1 & 1 \\
\hline
\end{tabular}


Table 2 Characteristics of the quenched ${ }^{241} \mathrm{Pu}$ standard solutions (reference date: 05.06.2009), and results of their measurements by LSC (reference date: 05.06.2009)

\begin{tabular}{llclll}
\hline Sample & $\begin{array}{l}{ }^{241} \text { Pu standard } \\
\text { activity }(\mathrm{Bq})\end{array}$ & $\mathrm{CCl}_{4}(\mu \mathrm{L})$ & $\mathrm{SQP}(E)$ & $\begin{array}{l}{ }^{241} \text { Pu measured } \\
\text { count rate }(\mathrm{cps})\end{array}$ \\
\hline 1 & $6.3 \pm 0.1$ & 0 & $854 \pm 2$ & $2.67 \pm 0.01$ & $42.3 \pm 1.1$ \\
2 & $6.3 \pm 0.1$ & 0 & $854 \pm 2$ & $2.72 \pm 0.02$ & $42.6 \pm 1.1$ \\
3 & $6.3 \pm 0.1$ & 22 & $831 \pm 2$ & $2.58 \pm 0.01$ & $40.4 \pm 1.0$ \\
4 & $6.3 \pm 0.1$ & 64 & $813 \pm 1$ & $2.44 \pm 0.02$ & $38.2 \pm 1.0$ \\
5 & $6.3 \pm 0.1$ & 89 & $795 \pm 1$ & $2.29 \pm 0.01$ & $36.0 \pm 0.9$ \\
6 & $6.3 \pm 0.1$ & 110 & $775 \pm 2$ & $2.11 \pm 0.01$ & $33.1 \pm 0.9$ \\
7 & $6.3 \pm 0.1$ & & $758 \pm 1$ & $1.95 \pm 0.01$ & $30.6 \pm 0.8$ \\
\hline
\end{tabular}

The theoretical relationship between both efficiencies $\left(\varepsilon_{241} \mathrm{Pu}\right.$ and $\varepsilon_{3 \mathrm{H}}$ ) is described by the polynomial formula (1):

$$
\begin{aligned}
\varepsilon_{241} \mathrm{Pu}= & k_{0}+k_{1} \cdot \varepsilon_{3} \mathrm{H}+k_{2} \cdot \varepsilon_{3}{ }^{2}+k_{3} \cdot \varepsilon_{3}{ }^{3} \\
& +k_{4} \cdot \varepsilon^{3}{ }^{4}{ }^{4}+k_{5} \cdot \varepsilon_{3}{ }^{5}
\end{aligned}
$$

The coefficients of the polynomial curve are: $k_{0}=$ $-0.1539 ; k_{1}=0.9259 ; k_{2}=-0.002041 ; k_{3}=3.614 \mathrm{E}-5$; $k_{4}=-3.449 \mathrm{E}-7 ; k_{5}=2.359 \mathrm{E}-9$. If the ${ }^{3} \mathrm{H}$ efficiency is $50.0 \%$, the ${ }^{241} \mathrm{Pu}$ efficiency is $44.3 \%$. This relationship is valid for only one scintillator and counting system, and must be established for each set of experimental conditions. The polynomial coefficients are slightly different to the ones obtained in a previous study by Corcho Alvarado et al. [9] due to the slight changes in the geometry (ex. volume of scintillation cocktail).

\section{Results and discussion}

The results of the measurements of the quenched ${ }^{241} \mathrm{Pu}$ standard solutions are presented in Table 2. The quench curve obtained from these measurements is shown in Fig. 1. The ${ }^{241} \mathrm{Pu}$ efficiency varied from 30 to $43 \%$, depending on the quenching parameter $\operatorname{SQP}(E)$. In a first attempt, the data was interpreted with a simple linear model. The linear fit describes well the data, however some deviations are observed for low and high quenching. In a second attempt, a quadratic model was used to fit the data. This resulted in better fittings, and therefore in a better representation of the data.

The results of the measurements of the quenched ${ }^{3} \mathrm{H}$ standard solutions are presented in Table 3 . The efficiency of ${ }^{3} \mathrm{H}$ versus the quenching parameter $\mathrm{SQP}(E)$ curve was determined experimentally (Fig. 2). Similarly to the quench curve for ${ }^{241} \mathrm{Pu}$ (Fig. 1), the relationship between the efficiency and the $\mathrm{SQP}(E)$ seems to better approach a quadratic function (Fig. 2).

The quadratic fit is then used to determine the ${ }^{3} \mathrm{H}$ efficiencies for the quench conditions $\operatorname{SQP}(E)$ of the ${ }^{241} \mathrm{Pu}$

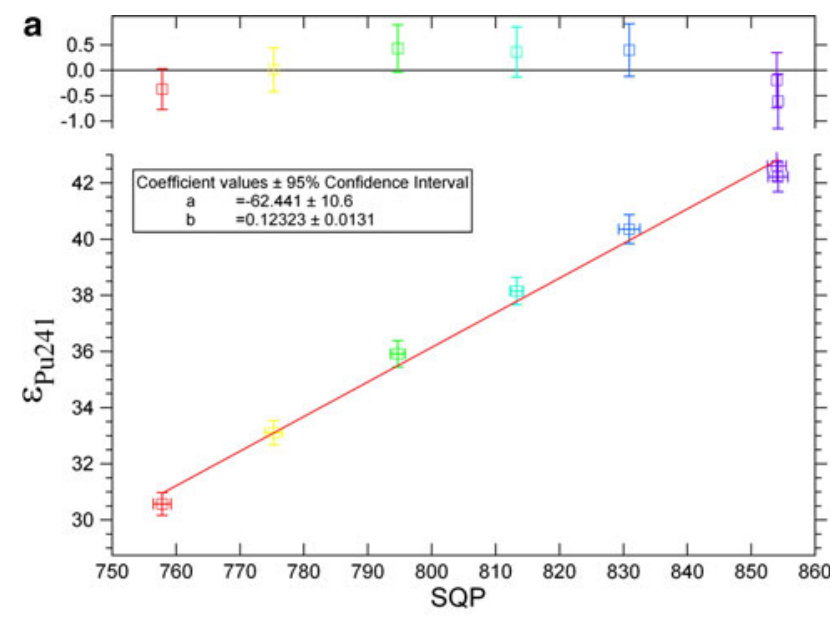

b
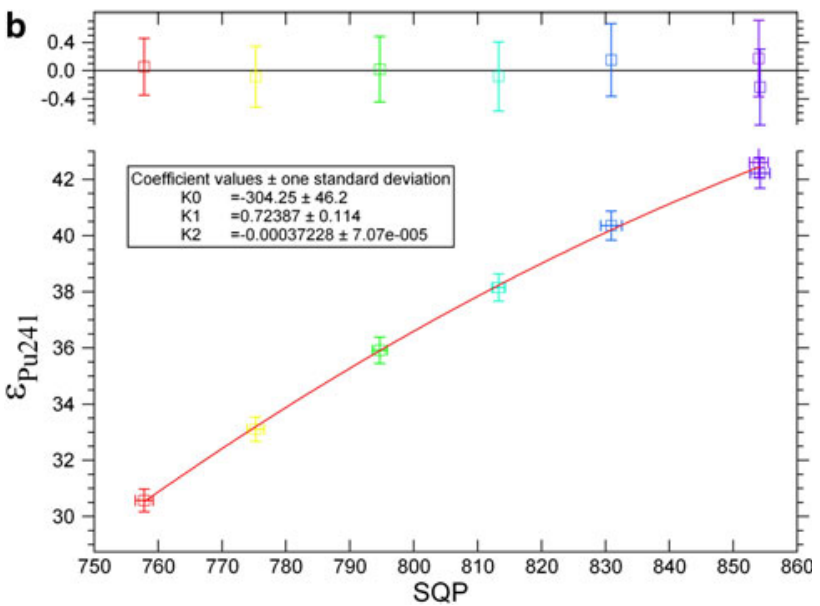

Fig. 1 Experimental quench curves obtained from the measurements of the quenched ${ }^{241} \mathrm{Pu}$ standard solutions: $\mathbf{a}$ with a linear fit and $\mathbf{b}$ with a polynomial fit

standard solutions reported in Table 1. The results are shown in Table 4. The CNET ${ }^{241} \mathrm{Pu}$ efficiencies are then derived from the ${ }^{3} \mathrm{H}$ efficiencies by using Eq. 1 . The CNET ${ }^{241} \mathrm{Pu}$ efficiencies varied in a range from 28 to $42 \%$, and they are about $10 \%$ lower than the ${ }^{3} \mathrm{H}$ efficiency (Table 4). The main sources of the standard uncertainty $(k=1)$ of the CNET method are given in Table 5. 
Table 3 Characteristics of the quenched ${ }^{3} \mathrm{H}$ standard solutions (reference date: 16.02.2009), and results of their measurements by LSC (reference date: 16.02.2009)

\begin{tabular}{llcccc}
\hline Sample & $\begin{array}{l}{ }^{3} \mathrm{H} \text { standard } \\
\text { activity }(\mathrm{Bq})\end{array}$ & $\mathrm{CCl}_{4}(\mu \mathrm{L})$ & $\mathrm{SQP}(E)$ & $\begin{array}{l}{ }^{3} \mathrm{H} \text { measured } \\
\text { count rate }(\mathrm{cps})\end{array}$ \\
\hline 1 & $348 \pm 7$ & 0 & $852 \pm 1$ & $161.5 \pm 0.3$ & $46.4 \pm 1.0$ \\
2 & 2 & $836 \pm 1$ & $156.4 \pm 0.3$ & $45.0 \pm 1.0$ \\
3 & $348 \pm 7$ & 4 & $821 \pm 1$ & $149.6 \pm 0.3$ & $43.0 \pm 1.0$ \\
4 & $348 \pm 7$ & 8 & $789 \pm 1$ & $131.8 \pm 0.2$ & $37.9 \pm 0.9$ \\
5 & $348 \pm 7$ & 10 & $766 \pm 1$ & $117.9 \pm 0.3$ & $33.9 \pm 0.8$ \\
\hline
\end{tabular}

The efficiency for ${ }^{241} \mathrm{Pu}$, derived from the efficiency of ${ }^{3} \mathrm{H}$ (CN method), is also shown

a
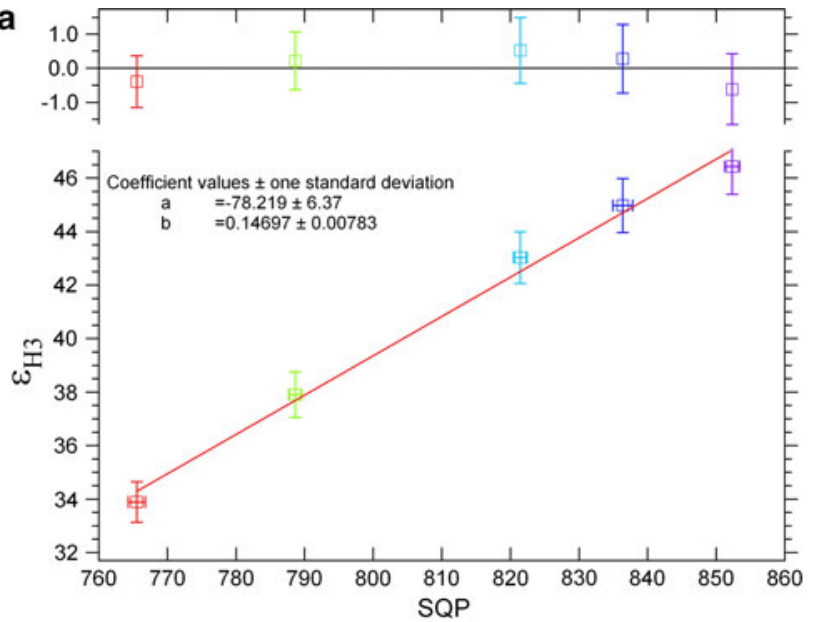

b
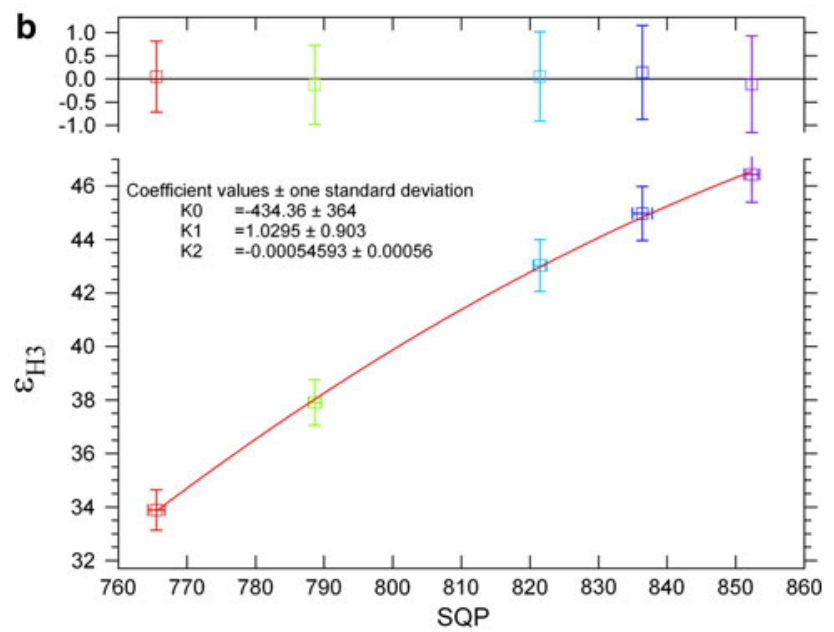

Fig. 2 Experimental quench curves obtained from the measurements of the quenched ${ }^{3} \mathrm{H}$ standard solutions: $\mathbf{a}$ with a linear fit and $\mathbf{b}$ with a polynomial fit

The results obtained by both calibration methods, the experimental quench correction curve and CNET, are shown in Fig. 3. We see that the efficiency of ${ }^{241} \mathrm{Pu}$ obtained by the CNET method is consistently lower than the one obtained by the quench correction curve method. Although the efficiencies of ${ }^{241} \mathrm{Pu}$ obtained by both calibration methods generally agree within their uncertainties,
Table 4 Efficiency for ${ }^{3} \mathrm{H}$ and ${ }^{241} \mathrm{Pu}$, determined by the CNET, for the quench conditions of the ${ }^{241} \mathrm{Pu}$ standard solutions

\begin{tabular}{llll}
\hline Sample & SQP $(E)$ & $\begin{array}{l}{ }^{3} \mathrm{H} \text { efficiency } \\
(\%)\end{array}$ & $\begin{array}{l}{ }^{241} \mathrm{Pu} \text { efficiency } \\
(\%)\end{array}$ \\
\hline 1 & $854 \pm 2$ & $46.7 \pm 1.0$ & $41.4 \pm 0.9$ \\
2 & $854 \pm 2$ & $46.7 \pm 1.0$ & $41.4 \pm 0.9$ \\
3 & $831 \pm 2$ & $44.2 \pm 0.6$ & $39.1 \pm 0.5$ \\
4 & $813 \pm 1$ & $41.9 \pm 0.7$ & $37.1 \pm 0.6$ \\
5 & $795 \pm 1$ & $39.0 \pm 0.7$ & $34.6 \pm 0.6$ \\
6 & $775 \pm 2$ & $35.7 \pm 0.6$ & $31.7 \pm 0.5$ \\
7 & $758 \pm 1$ & $32.3 \pm 1.1$ & $28.7 \pm 0.9$ \\
\hline
\end{tabular}

some discrepancies are especially observed at higher quenching factors (lower efficiencies).

The consistent trend of the CNET to produce lower efficiencies is possibly attributed to an inaccuracy of the computer models to fully reproduce the efficiency. This inaccuracy may be due to the fact that the beta decay of ${ }^{241} \mathrm{Pu}$ is a first forbidden and non-unique transition while the CNET code assumes an allowed transition [20].

A previous study has also shown that major discrepancies remained between different standardization methods for ${ }^{241} \mathrm{Pu}$ [14]. In this study, the activities obtained by the liquid scintillation Triple to Double Coincidence Ratio (TDCR) standardization method were consistently lower by $7-8 \%$ than the ones obtained by the liquid scintillation CNET and the ${ }^{241} \mathrm{Am}$ ingrowth methods [14]. These disagreements were not attributed to the models and/or calculation codes, and the discrepancy was, however, not resolved [14].

In any case, both methods agree well for low quenched samples (high $\mathrm{SQP}(E)$ ). In a previous study conducted by Corcho Alvarado et al. [9], the CNET method was used for determining the ${ }^{241} \mathrm{Pu}$ efficiency in nearly the same counting conditions (ex. geometry) as our present study. The typical quenching factors $(\operatorname{SQP}(E))$ measured in this study varied between 830 and 850 , which corresponds to an efficiency range of $39-42 \%$. This means that all the samples were in the quenching region where the CNET method 
Table 5 Main sources of the standard uncertainty $(k=1)$ in the activity of ${ }^{241} \mathrm{Pu}$ as determined by the CNET method

\begin{tabular}{ll}
\hline Type-B uncertainties & \\
Background (\%) & 0.045 \\
Half-life (\%) & 0.261 \\
Weighing (\%) & 0.099 \\
Dilution factor (\%) & 0.474 \\
Tracer activity + quenching (\%) & 2.012 \\
Decay scheme (\%) & 1.160 \\
Combined type-B uncertainty (\%) & 2.388 \\
Type-A uncertainties & \\
Counting statistics (\%) & 0.610 \\
Combined type-A uncertainty (\%) & 0.610 \\
Quadratic sum of type-A and type-B uncertainties (\%) & 2.464 \\
\hline
\end{tabular}

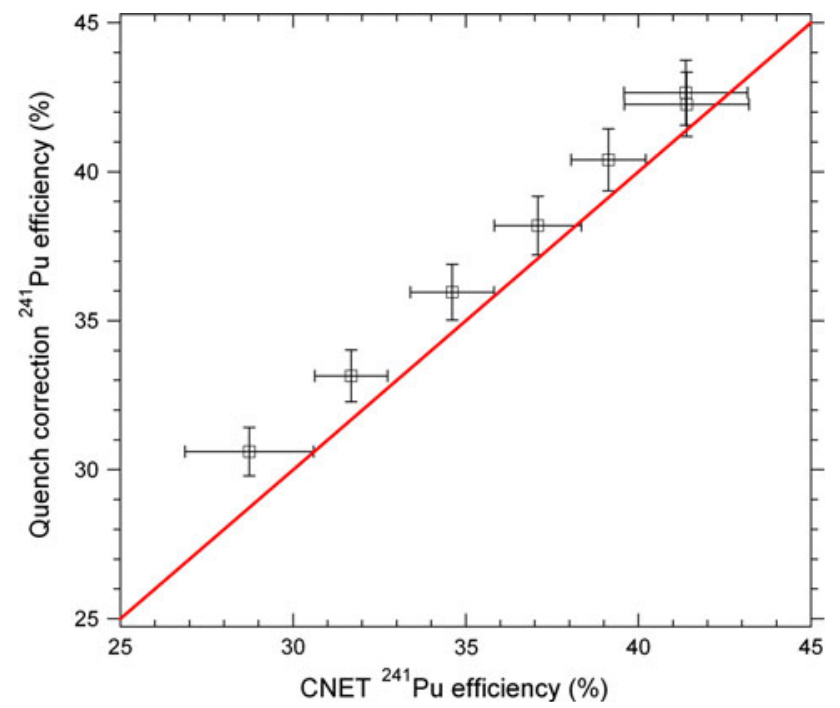

Fig. 3 Quench correction curve efficiency versus CNET efficiency. Line represents the 1:1 correlation. Uncertainties are 2-sigma

and the quench correction curve are in good agreement (Fig. 3).

\section{Conclusions}

The results of this study confirm that both, the quench correction curve and the CNET methods, are valid for the determination of the ${ }^{241} \mathrm{Pu}$ efficiency in the Quantulus 1220 for the typical counting conditions. The CNET method is therefore useful when certified reference solutions of ${ }^{241} \mathrm{Pu}$ are not available for the efficiency calibration.

\section{References}

1. Gascó C, Antón MP, Espinosa A, Aragón A, Alvarez A, Navarro N, García-Toraño E (1997) Procedures to define Pu isotopic ratios characterizing a contaminated area in Palomares (Spain). J Radioanal Nucl Chem 222:81-86

2. Liong Wee Kwong L, La Rosa JJ, Lee SH, Povinec PP (2001) Liquid scintillation spectrometry of beta-emitters in marine samples. J Radioanal Nucl Chem 248(3):751-755

3. Liong Wee Kwong L, Gastaud J, La Rosa J, Lee SH, Povinec PP, Wyse E (2004) Determination of ${ }^{241} \mathrm{Pu}$ in marine samples using co-precipitation with rare earth fluoride and liquid scintillation spectrometry. J Radioanal Nucl Chem 261(2):283-289

4. Struminska DI, Skwarzec B (2006) Pu-241 concentration in southern Baltic Sea ecosystem. J Radioanal Nucl Chem 268(1): $59-63$

5. Hou X (2007) Radiochemical analysis of radionuclides difficult to measure for waste characterization in decommissioning of nuclear facilities. J Radioanal Nucl Chem 273(1):43-48

6. Martin JE (1986) Determination of ${ }^{241} \mathrm{Pu}$ in low-level radioactive wastes from reactors. Health Phys 51(5):621-631

7. Ikäheimonen TK (2000) Measurement of ${ }^{241} \mathrm{Pu}$ in environmental samples. J Radioanal Nucl Chem 243(2):535-541

8. Varga B, Tarjan S (2008) Determination of ${ }^{241} \mathrm{Pu}$ in the environmental samples. Appl Radiat Isot 66(2):265-270

9. Corcho Alvarado JA, Chawla F, Froidevaux P (2011) Determining ${ }^{241} \mathrm{Pu}$ in environmental samples: case studies in alpine soils. Radiochim Acta 99(2):121-129

10. Hakanen M, Jaakkola T, Korpela H (1984) Simultaneous determination of $241 \mathrm{Pu}, 238 \mathrm{Pu}$ and $239,240 \mathrm{Pu}$ in low activity environmental samples. Nucl Instrum Methods Phys Res 223(2-3): 382-385

11. Moreno J, La Rosa JJ, Danesi PR, Vajda N, Burn K, De Regge P, Sinojmeri M (1998) Determination of ${ }^{241} \mathrm{Pu}$ by liquid scintillation counting in the combined procedure for Pu radionuclides, ${ }^{241} \mathrm{Am}$ and ${ }^{90} \mathrm{Sr}$ analysis in environmental samples. J Radiat Radiochem 9:2

12. Broda R, Cassette Ph, Kossert K (2007) Radionuclide metrology using liquid scintillation counting. Metrologia 44:S36-S52

13. Payne RF, Clark SB, Elliston JT (2008) Radioanalytical approach to determine ${ }^{238} \mathrm{Pu},{ }^{239}+{ }^{240} \mathrm{Pu},{ }^{241} \mathrm{Pu}$ and ${ }^{241} \mathrm{Am}$ in soils. J Radioanal Nucl Chem 277(1):269-274

14. Collé R (2009) Radionuclidic standardization by primary methods: an overview. J Radioanal Nucl Chem 280(2):265-273

15. Gunther E (2002) LSC 2001, advances in liquid scintillation spectrometry. In: Mobius S, Noakes JE, Schonhofer F (eds) Radiocarbon. University of Arizona, Tucson

16. Coursey BM, Lucas L, Grau Malonda A, García-Toraño E (1989) The standardization of plutonium-241 and nickel-63. Nucl Instrum Methods Phys Res A279:603

17. Grau Carles A, Rodriguez L, Grau Malonda A (1994) Standardization of I-125, Sr-85 and Cd-109 by CIEMAT/NIST method. Appl Radiat Isot 45:461

18. Grau Carles P, Grau Malonda A (2001) Free parameter, figure of merit and ionization quench in liquid scintillation. Appl Radiat Isot $54: 447$

19. Grau Malonda A (1999) Free parameter models in liquid scintillation counting. Editorial CIEMAT, Madrid. ISBN 84-7834287-7

20. Loidl M, Rodrigues M, Censier B, Kowalski S, Mougeot X, Cassette P, Branger T, Lacour D (2010) First measurement of the beta spectrum of ${ }^{241} \mathrm{Pu}$ with a cryogenic detector. Appl Radiat Isot $68(\mathrm{I}): 7-8$ 